\title{
Research on the Financial Supports to Economic Development of Ethnic Regions in China
}

\author{
Jianshen Zhang ${ }^{1}$ \\ ${ }^{1}$ School of Economics, Northwest University for Nationalities, Lanzhou, China \\ Correspondence: Jianshen Zhang, Associate Professor, School of Economics, Northwest University for Nationalities, \\ Lanzhou 730124, China. E-mail: jingjizjsh@163.com
}

Received: January 21, 2015

Accepted: February 3, 2015

Online Published: March 9, 2015

doi:10.5430/rwe.v6n1p184

URL: http://dx.doi.org/10.5430/rwe.v6n1p184

\begin{abstract}
Generally speaking, the economic development in ethnic regions is characterized by relative backwardness, huge gap with mainstay economy, slow rate of economic development, low degree of socialization and single economic structure. To accelerate economic and social development of ethnic regions, the financial supports policies with national features is needed to promoting rapid economic development and developing small and medium-sized Banks, establishing financial reform experimental district and perfect insurance and guarantee system in ethnic regions.
\end{abstract}

Keywords: the ethnic regions, economic development, financial supports

\section{Introduction}

Unbalanced economic development among various nations exist multi-national country all over the world. The existence of the gap affects the overall development of the nation's economy. It will promote the division of the work cooperation, and make economic prosperity, social stability when there is tiny gap among different regions. However, it will hinder the unified market, resulting in slowing economic development and unable to optimize resource allocation, and even causing social unrest once the gap is too large.

After the Sixteenth CPC National Congress, CPC central committee issued vital file about promoting the development of ethnic regions saying Decision of CPC Central Committee and the State Council of further strengthen the national work and accelerate economic and social development of ethnic and ethnic region. The biggest bottleneck we have to face is the lack of funds for the rapid economic development in the ethnic regions. The ethnic regions are mainly distributed in the border and remote parts of inland provinces, most of them lie in the west of the geographic distribution including five national autonomous regions, thirty autonomous prefectures, one hundred and twenty minority autonomous counties, around one thousand and two hundreds national townships. Because of various factor such as history, geography, and nature of the economic aggregate, economic foundations is poor, social development is slow compared with the developed regions.

The ethnic regions must clearly understand their own strengths and weaknesses, making full use of congenital advantage of abundant resources, relatively cheap labor, and unique ethnic customs, and try to make up for shortcomings at the same time, improve the investment environment, foster strengths and circumvent weaknesses, and to narrow the gap with the east-central developed regions. The bottleneck is the absence of adequate funding. Especially Chinese economy under the condition of the middle of industrialization financial resources is not enough, and economic development in national regions needs the financial industry to provide a lot of financial support. It is important to explore a right road to promote the financial sustainable development in ethnic regions. Financial industry is not inherent. It comes into being in a more developed economy, and it has the function of promoting economic development. Economic development is poor in ethnic regions, and it has the heavy task of modernization construction. China is still in its primary stage of socialism, the economy is in the middle of industrialization; GDP per capita ranks behind many countries; the task of economic development is hard; the government disposable financial resources are still limited; so it is impractical to throw the large amounts of money into ethnic regions. It is particularly urgent for supporting the development of economy in ethnic regions to provide funds supports from the financial industry. 


\section{Status Analysis of Economic Development in the Ethnic Regions}

Though the ethnic regions have certain resource advantage, because of the historical process and some objective reality reason, there are still some restraints on the economic development, which make a certain gap of economic development level between the most of the ethnic regions and overall level of economic development of the country.

\subsection{Economic Development Is Generally Slow}

There are many factors restricting the progress of minority economy, and there are some following non-economic factors: The first is the closeness of economic relationships caused by geopolitical disadvantages. Most of the minorities live in desolate and remote regions generation after generation, and minorities are far away from the political and economic center. Because the majority of ethnic minorities living in the harsh natural environment; and traffic is inconvenient; information is blocked, which make the economy has the characteristic of closeness. The second is closed to consciousness and backward ideas of ethnic minorities. Due to the minority is located in remote, and far away from the political and cultural center; under the influence of different religious beliefs, customs and habits, living habits, living taboo, at the same time, which lead and strengthen the traditional cultures of minorities and conservative ideas, and because of the sealing, the conservatism perform so incisively, the conservative national consciousness is not conducive to communicate with other nationality, adopted the advantage of developed regions, and overcome its disadvantage, so it greatly restricted the economic development of ethnic minorities. The third is ethnic education degree is generally low, and it makes the innovation bottleneck. Both from the quantity and quality of the human resources and infrastructure of the education system, it can be seen from all over the world, ethnic education level is pretty low, the human resources quality is difficult to adapt to the demands of the development of knowledge economy.

\subsection{Low Degree of Productive Socialization and Insufficient Market Development}

The most ethnic regions is in the lower stage of social development, and some of them even in nomadic tribal society, the level of medical and health education, culture is extreme low, commodity economy is not developed, the market development degree is insufficient. Degree of social development is low, which limit market scope, extension of dividing the work, formation of capital and development of comparative advantage. There is the specific performance. Firstly, the market system is not perfect, it means to market scope is tiny, few kinds in commodity market, and the matching factor market of financial, labor, technology, information is delayed. Secondly, market subjects develop slowly, it means industry foundation is weak, production scale is narrow, and management level is low. From the basic theory of economics, only in a relatively perfect market mechanism, does the price reflect the change of supply and demand, achieve reasonable configuration and effective utilization of resources and lead to the emergence of alternative sources, but in most of the minority economy, market development is insufficient. The distorted price impedes the efficient allocation and rational flow of resources, resulting in inefficient economic growth.

\subsection{Economic Structure Is Single, and the Traditional Economy Plays an Important Role}

In most minorities, industrial basis is weak, the development of the tertiary industry is slow, the traditional agriculture and animal husbandry still accounted for a large proportion, the livelihood of many ethnics mainly rely on the combine of simple labor, traditional technology and small piece of land, it is in great need of technology and capital.

Table 1. Industry structure in ethnic regions and China as a whole

unit: $\%$

\begin{tabular}{lccccccccc}
\hline & $\begin{array}{c}\text { Inner } \\
\text { Mongolia }\end{array}$ & $\begin{array}{c}\text { Guang } \\
\text { xi }\end{array}$ & Guizhou & Yunnan & Tibet & Qinghai & $\begin{array}{c}\text { Ning } \\
\text { xia }\end{array}$ & $\begin{array}{c}\text { Xing } \\
\text { jiang }\end{array}$ & China \\
\hline $\begin{array}{l}\text { Primary } \\
\text { industry }\end{array}$ & 15.1 & 22.4 & 18.5 & 18.9 & 19.1 & 11.6 & 12.7 & 19.6 & 12.6 \\
$\begin{array}{l}\text { Secondary } \\
\text { industry }\end{array}$ & 45.5 & 37.1 & 42.4 & 41.8 & 25.3 & 48.7 & 47.7 & 44.7 & 47.5 \\
$\begin{array}{l}\text { Tertiary } \\
\text { industry }\end{array}$ & 39.4 & 40.5 & 39.1 & 39.3 & 55.6 & 39.7 & 39.8 & 35.7 & 39.9 \\
\hline
\end{tabular}

Source: Chinese statistical yearbook 2008 
Since agriculture itself is the industry with low efficiency, and lots of agricultural production mode of minorities is the labor organization form of small scale economy combination in family, most of them still remain the original production mode of "slash-and-burn cultivation", agricultural output completely dependent on the size of the labor input and the weather. Because the agricultural technology hasn't changed for a long time, agricultural productivity level is low, hard-working for one year only enough to feed the family. And the industrial structure dominated by farming leads to urban-rural patterns of traditional agricultural society structure, which make the economic development of ethnic regions lack of the necessary motive force, is not conducive to the accumulation of these ethnic minorities development ability.

\subsection{Strong Anaclisis of the Ethnic Regions to Central Government}

From the situation in China, anaclisis of underdeveloped ethnic in human, financial and material resources is still obvious. Food of most ethnic cannot be self-sufficient, it relies on the inlet grain from developed regions to maintain the basic survival needs; industrial development level is low, especially light industry foundation is weak, self-sufficiency degree of basic means of production and consumer goods is low, it rely on outside input; most productions of ethnic minorities are primary resource products, and the market point is mainly in developed regions, even the trading pattern exist price distortion and dual loss of value, the inequality of inter regional trade is still happening.

Compared with the national overall level, especially with eastern coastal regions, there still exist obvious gap in economic aggregate, developmental level, industrial restructuring, degree of opening to the outside world and urbanization level in ethnic regions. In the early stage of reform and opening up, the government uses the strategy of unbalance development, the lack of a national policy support in ethnic regions is the external cause of slow development. From the internal reasons, delay of self-reform in ethnic regions also causes insufficient power of economic development in a certain degree. While insufficient financial support is one of the main reasons.

\section{Main Problems of Financial Supports to Ethnic Regions}

\subsection{Overall Financial Development and Capital Market Development in Ethnic Regions Are Backward}

Overall financial development in ethnic regions and monetization level is insufficient. The degree of monetization in the economic cycle is pretty low. On the one hand is in that the natural economy in national regions occupies a larger proportion, and on the other hand is financing institution and economic structure in ethnic regions is unreasonable. The proportion of ethnic area loans accounted for the federal loans is lower than ethnic area GDP accounted for the national GDP, the correlation ratio of ethnic regions is significantly lower than that of national. It shows that the level of financial development in domestic regions is lower than national level.

Table 2. The proportion of loan balance in ethnic regions and GDP to that of national level

\begin{tabular}{lcccccc}
\hline & 2003 & 2004 & 2005 & 3006 & 2007 & 2008 \\
\hline proportion of loan & 6.59 & 6.49 & 6.12 & 5.87 & 5.94 & 5.8 \\
proportion of GDP & 8.37 & 8.41 & 8.57 & 8.85 & 9.15 & 8.54 \\
\hline
\end{tabular}

Source: Calculate according to the Chinese statistical yearbook 2006.

Capital market as a way of direct financing, it can reflect the financial market transaction relationship better, and the establishment has significant sense to promote and deepen the financial development in ethnic regions. But overall capital market development in ethnic regions is slow, direct financing channel is narrow: the stock market is not developed, including the number of listed companies is small, their financing capacity, economic benefits are low; the development of bond market is backward; the number of securities institutions is small, and its development is pretty low.

\subsection{Financial Institutions and Financial Instruments in Ethnic Regions Are Less}

Along with the opening up to the outside world and the establishment of market economic system, the eastern China improves the system of financial institutions constantly. Firstly, it has formed diversified financial pattern of state-owned commercial bank, policy bank, joint-equity commercial bank, non-bank financial institutions and foreign financial institutions, and the business proportion of the four state-owned commercial bank is decreasing. In addition, there is lots of informal finance in the coastal regions of Guangzhou. Fijian, Zhejiang, etc, but the financing institution in ethnic regions is occupied by the four state-owned commercial bank. Secondly, the number of financial 
institutions in the eastern region is further expanding rapidly. We take an example of ICBC, its regional branches set up in eastern region accounts for $46 \%$, the proportion in the western region only accounts for $20.3 \%$, this has 2,079 in Guangzhou, 1, 493 in Jiangsu, 1, 631 in Shandong. The situation is similar in the other state-owned commercial Banks. As for the financial institutions in national regions, firstly, the diversified financial pattern is not in final form yet. The four state-owned commercial banks occupy the dominant position. Though the ten joint-stock commercial banks such as China Merchants Bank, China Minsheng Banking Corp., China Everbright Bank has landed in ethnic regions. They mainly set up a few branches in the center of the multi-national area. Although foreign financial institutions have poured into China after Chinese entry of WTO, almost no institutional step into the ethnic regions. The characteristic of less numbers and a single category in ethnic regions restrain the diversified development of financial instruments directly, and the direct performance is the lack of financial instruments.

\subsection{Regional Capital Loss Seriously, Which Intensified the Conflict between Capital Supply and Demand}

Economic development in eastern China is fast, and its investment environment is fine, marginal efficiency of capital is obviously higher than that of national regions, the investment risk is also lower than the national regions, and it has more ways to spread risk. Although China has injected a lot of money to support ethnic regions economic development for a long time, capital flows through various channels to the eastern region, such as credit funds directly focus to big cities and developed regions through funds deposited, net capital lending and financing institution. Especially the rapid growth of the postal savings, the absorption of funds focus on head office by the people's bank of China, unified deployment of use, directly affects fund supply of the national regions, someone called this phenomenon the "pumper".

Gap between eastern and western capital market, making capital gathered in the eastern region through the capital market, and increase the funding gap in national regions, financial institutions in national regions become pumper which extract money from ethnic regions in some sense.

\section{Countermeasure and Suggestion of the Financial Support in Ethnic Regions}

In the modern economy, factors to promote the economic development in addition to the land, capital, labor consists the three basic elements, some new factors on the economic development of the contribution rate is rising, among these new factors, the status and function of financial is more and more important. The regional structure of the financial development in China is similar to economic development, it appear obvious gradient difference, financial development in western ethnic regions is in a state of shallow and low development, financial markets in the western ethnic regions obviously fall behind the eastern region in quantity expansion and quality improvement. In the market economy, increasing financial dependence, the shallow financial development state in the western ethnic regions will hamper the effect of development of the west regions, inhibition capital formation in the western ethnic regions, hinder the optimization of industry structure in western ethnic regions, and decrease the operational efficiency of financial and economic in ethnic regions, which restrict development of western regions and long-term stability of the ethnic regions economic growth. Thus, it is particularly important to research financial support in the economic development in western ethnic regions, the development of ethnic regions economy must strengthen the financial supports.

4.1 Giving Full Play to the Financing Function of Policy Financial Institutions, and Actively Raise Long-term Credit Funds

As a result of feebleness of economy in ethnic regions, it is impossible to effectively improve the obvious lack of functional existing in the current financial system. Therefore, we must repositioned and play to the role of the existing policy finance, and give full play to the national credit advantage under finance policy, make up for the consideration of the financial system in ethnic regions, and improve the market environment of the commercial finance. Firstly, we must solve the problems of capital source that trouble policy-based financial institutions for a long time. The capital source of policy-based financial institutions relies on issuing policy financial bonds, and it is obviously not enough to increase financial support for ethnic regions. Issuing national development finance bonds are considered. Special to raise funds for national development; taking some financial savings into capital sources of policy financial institutions to solve the insufficient funds in policy-based financial institutions. Secondly, we should strengthen the management of policy-based financial bank, control the loan object and scale of policy-based financial bank strictly, long-term loans should be mainly used in medium and long term key construction projects and resource development, especially for some project conform to the national macroeconomic policy and industrial policy and good for ecological environment construction and protection. At present, China Development Bank undertakes the provision of most policy capital. Since China Development Bank provide consideration to fund requirements from all over the China, it is not possible to pour excessive investment in ethnic regions, therefore, it is worthwhile 
considering establishment the national development bank for government to provide policy financial support for ethnic regions. The positioning of the national development bank is a policy-based bank providing service for ethnic regions. The main capital source includes national founds and government in ethnic region founds.

\subsection{Establishing Multi-layered Small and Medium-sized Banking Systems in Ethnic Regions}

Firstly, the small and medium-sized banks should be set up through various channels. Transforming the county branch of state-owned banks to independent local bank; then, reconstruct some small and medium-sized banks absorbing private capital, such as community banks; in addition, perfect rural financial service system, convert rural credit cooperative to local bank gradually, such as rural banks. Secondly, giving necessary policy support, providing a loose and harmonious environment for the development of small and medium banks. Small and medium-sized banks are given priority to financial retail, the costs are high, and the profit is low, so they cannot stand the same tax with large bank, we should give clear preferential policies in tax to small and medium-sized banks. Then, we should raise a loan interest rate floating range. Because the retail price is greater than the wholesale price meeting the market rules, as the price of capital, loan interest rate between large bank and small and medium-sized bank should be different. In addiction, government-funded capital lead to setting up an ethnic regions loan guarantee fund, most of the found is given by fiscal investment of county and township government, the rest is given by leading enterprises and other economic entity. The fund will mainly face peasant household, rural small businesses, and individual business in ethnic regions, and solve the key problem of wholesale funding guarantee, reduce the small and medium-sized bank loan risk, improve asset quality. Finally, we should promote the construction of a deposit insurance system, and formed financial institutions risk sharing mechanism of the market gradually, to strengthen the power and stress of small and medium-sized banks, and reduce the moral hazard. Thirdly, regulate the behavior of small and medium-sized bank, and run business characteristic. Small and medium-sized banks should refer to international practice and combine with the characteristics of the ethnic regions, then locate the functions and market, run their own business characteristics, such as community banks should provide convenient and quick, low cost, personalized financial services for local residents or small and medium-sized enterprises, protrude the characteristics of universal bank; village bank should provide standardized banking products and services for local farmers, agriculture and rural economy, protrude the characteristics of cooperative system, combined with local actual, design various kinds of financial products that meet the need of farmers and rural production in order to satisfy the need of different customer group in the countryside. Such as loans, they can exploit different loans that provided for planting and raising a large farmer and rural small businesses. Only the small and medium-sized bank develops their own characteristics, promote business innovation constantly, and provide characterization of financial services, can they attract and retain customers, take place in market and avoid cutthroat competition.

\subsection{Establishing Insurance System and Credit Guarantee System That Suit for Ethnic Regions Economic Development}

Setting up the policy insurance company in ethnic regions. The first consists of establishing the premium subsidy system, playing the enthusiasm of supporting insurance by central and local government. Such as agricultural insurance, in other countries, fully supports agricultural insurance has become an important measure protecting agriculture by government. In USA, government provides the allowance of $30 \%$ of the insurance premium for the crops participates, the allowance in Canada and Japan is $50 \%$, and it is worth using as the reference. The second is to research formulating supporting policies, such as capital, tax and reinsurance, etc. The third is pushing forward agricultural policy insurance institutions works steadily with appropriate agricultural insurance business scope, planting of pastoral region and breeding of insurance products according to characteristics of agriculture and animal husbandry development in their respective jurisdictions. It can be established planting and breeding risk funds or benefit association to strengthen training and supporting effect for planting and raising farmer. The specialized households can drive economic and social development of ethnic minorities and ethnic regions and advance the farmers' income. Small insurance amount is tiny, the premium is low, the procedure of insure and settlement of claims is convenient, and it is suitable for the level of rural economic development and farmers' consumption. Small insurance can take root in the countryside, and it can provide timely help for low income farmers, and it can provide postal insurance for low income populations in rural and the urban, it is a kind of market-oriented effective financial assist method, it is widely used in more and more countries and regions in the world.

Establishing agencies with policy credit guarantees will be beneficial. Guarantee funds are raised by the central and local government credit guarantee funds budget, and it is associates with the government related functional departments. The features of policy guarantee agencies should be policy-regulated, and it should not be engaged in the investment business other than loan guarantees rather than in line with the principles of meager profit aiming at 
the long-term sustainable development for enterprises, agriculture and rural economy in ethnic regions, and sharing the financing risk of financial institutions. Policy guarantee agencies reflect policy will be of government, and it makes up the insufficient supply of credit guarantee market behavior in ethnic regions largely at this stage.

\subsection{Setting up Financial Reform Test Regions and Build Regional Financial Center in Ethnic Regions}

Apart from the better comprehensive resources, economic development in eastern regions has also benefited from "reform experiment". To make up for the artificial lag of financial reform and financial innovation in ethnic regions during nineties in 20th century, we can set up financial reform experimental zone in the capital city in national regions with better economic condition and relatively stable environment. Guangxi is the only edgewise and coastal province among ethnic regions, adjacent to the economically developed pearl river delta, facing southeast Asia, and Nanning, the capital of Guangxi, is the permanent site of Asean-China Expo, location advantage is obvious, its economy shows a trend of rapid development in recent years. Economic Zone of Beibu Gulf rise for the national development strategy after the development program was approved by central government in January 2008, the goal is to build a new highland of international economic cooperation and Chinese coastal development. Economic Zone of Beibu Gulf is also a comprehensive reform pilot area. Therefore, making Guangxi a financial reform pilot area is considerable, and Nanning a financial center. On the one hand it can give play to "demonstration effect", on the other hand it can attract foreign capital with more financing channels and capital sources for development of ethnic regions. In the reform and innovation, we can make experiments establishing financial holding companies to take mixed management, in addiction, introducing all kinds of capital to build private small and medium-sized banks actively to broaden the restrictive entrance condition of foreign financial institutions, and perfecting the financial system constantly.

\section{References}

He, Jian. (2007). Key Issues of the financial supports on the countryside economy in ethnic regions in China. Commercial Time, (10), 139-141.

Liu, Shangrong. (2009). The financial Countermeasures against promoting economic development in ethnic regions in China. Qinghai Social Science, 6, 101-109.

Qi, Shoucheng. (2007). On the financial supports of construction of new countryside in ethnic regions in China. Weihai engineering Institute Journal (Social Science Edition), 4, 45-52.

Wang, Xinshong. (2009). On Strategy Research of financial supports to Qinghai Economic Development. Qinghai Social Science, 3, 71-78.

Wu, Yan. (2006). Research on bank loan market in ethnic regions in China. Heilongjiang Ethnic Journal, 3, 121-129.

Zhang, Jiashou. (2010). The financial policy analysis of accelerating ethnics and ethnic regional economic development. The Regional Financial Research, 1, 112-119. 